\title{
ISfTeH TRIBUTE TO PROFESSOR LOUIS LARENG (1923-2019)
}

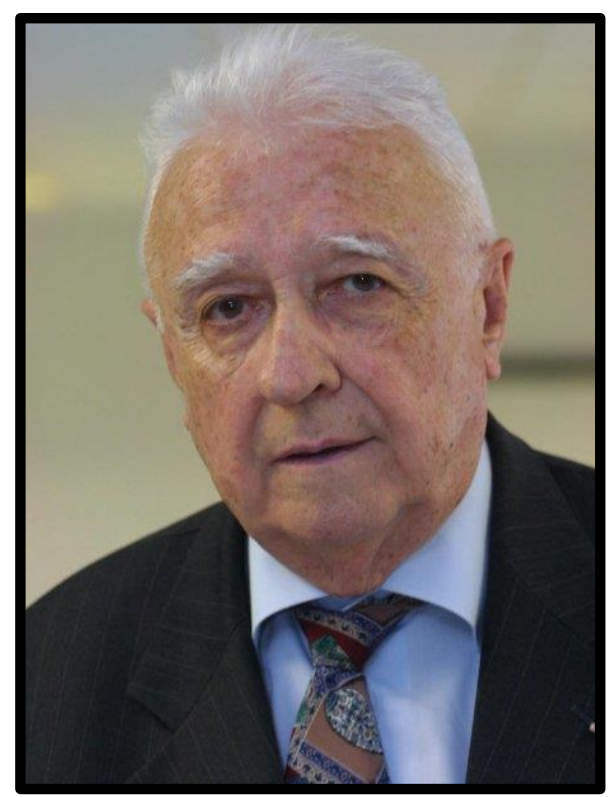

Louis LARENG was born on April $8^{\text {th }}, 1923$ in the village of Ayzac-Ost, at the foot of the Pyrenees, at the southern end of Gascony, France, where he spent his childhood and throughout his life retained the simultaneously melodious and gravelly local accent. He studied medicine in Toulouse and spent his entire professional career within the hospital system of this city. He was an anaesthesiologist, a speciality that he taught as Professor of Medicine. A pioneer of emergency departments in France, he created and codified the EMERGENCY MEDICAL SERVICE (Service d'Aide Médicale Urgente or SAMU in French) in 1967, and worked constantly for legal recognition of this original organization, which was given in 1992 .

He was also a founder of the Paul Sabatier University in Toulouse, where he later became Emeritus Professor in 1992. It was at this time that he took up the fight for Telemedicine, a discipline that was almost unknown in France and that he would advocate at the highest levels, with determination or even stubbornness, until its recognition through the enactment of national laws in 2004. Then in 2010, the famous Hospitals, Patients, Health and Territories Act (HPST or Bachelot law in French), whose article 78, became a true legal birth certificate for telemedicine in France. To get there, he had to make himself heard, and then listened to, in all the relevant political and technical circles, which often had trouble following this unconditional enthusiasm.

Louis Lareng launched telemedicine and telehealth, and ensured their best possible applications in his region of the Midi-Pyrénées, first with the public charity Network
Telemedicine (2003), where he held various positions of responsibility, and later the administration of the MidiPyrenees Telehealth Cooperation Group in March 2011. The creation of the European Institute of Telemedicine, of which he was the Director, and of the European Society of Telemedicine and eHealth, where he was the President, enabled him to make his work and achievements known in France and abroad. Considered one of the pioneers of telemedicine in the world, he was part of the editorial committee of many specialized journals in the field. He authored 896 publications and papers that are milestones and evidence of his various medical activities throughout his long career. Many scientific societies have had him as President or as an active member. In particular, he was a founding member, in 1997, of the International Society for Telemedicine (ISfT), which later became the ISfTeH, and a member of the Board of the society from 2007 to 2009.

But Louis Lareng was not only this doctor with a permanent commitment to the best care for patients. He was also a man involved in the social and political life of his village where he was mayor; his region where he was an elected representative, municipal councillor and regional councillor; and his country where he served as an adviser to several ministers of health. At the crossroads of his skills, he has worked for the Red Cross in his region as well as for Public Safety services at national level, where he was President of the National Federation. Louis Lareng has been honoured many times for his work and achievements through multiple awards and recognitions, but especially as Commander of the "Palmes Académiques", Commander of the National Order of the "Légion of Honneur", and Officer of the National Order of Merit.

An in-depth review of the life of this eminent member of the ISfTeH, with his unwavering commitment to the existence of telemedicine and telehealth and their integration into the daily practices of health professionals, led the ISfTeH to pay him homage, at the $10^{\text {th }}$ anniversary of Med-e-Tel in 2012, with a special lifetime achievement award. This award has since been named the Louis Lareng Prize, with only three other recipients since its inception.

Andre Petitet

Yunkap Kwankam

DOI: https://doi.org/10.29086/JISfTeH.8.e2

Copyright:@ The Authors 2020

Open access, published under Creative Commons

Attribution 4.0 BY International Licence

Crossref 